\title{
Significance of olive oil in the host immune resistance to infection
}

\author{
María A. Puertollano ${ }^{1,2}$, Elena Puertollano ${ }^{1}$, Gerardo Álvarez de Cienfuegos ${ }^{1}$ and Manuel A. de Pablo ${ }^{1 *}$ \\ ${ }^{1}$ Unit of Microbiology, Department of Health Sciences, Faculty of Experimental Sciences, University of Jaén, 23071, Jaén (Spain) \\ ${ }^{2}$ Department of Metabolism and Nutrition, Consejo Superior de Investigaciones Cientificas (CSIC), 28040 Madrid (Spain)
}

\begin{abstract}
The effects exerted by polyunsaturated fatty acids (PUFA) on immune system functions have been investigated in recent years. These studies have reported the important role that $n$-3 PUFA play in the diminution of incidence and severity of inflammatory disorders. Nevertheless, less attention has been paid to the action of monounsaturated fatty acids (MUFA) upon the immune system. The administration of a diet containing a high amount of olive oil in experimental animals produces a suppression of lymphocyte proliferation, an inhibition of cytokine production and a reduction in natural killer (NK) cell activity. Despite these alterations in immune functions, it has been reported that olive oil-rich diets are not as immunosuppressive as fish oil diets. An important aspect in immunonutrition is focused on the relationship between fats, the immune system and host resistance to infection, particularly when these nutrients are supplied to patients at risk of sepsis. Different studies have determined that olive oil-rich diets do not impair the host resistance to infection. Therefore, olive oil constitutes a suitable fat that may be applied in clinical nutrition and administered to critically ill patients. In the present review, we summarize the current knowledge on olive oil and immune system functions, the biological consequences derived from the administration of diets containing olive oil and the impact of olive oil on immune defence.
\end{abstract}

Olive oil: Immune system: Host resistance

Epidemiological studies supported by experimental data from both animals and humans, have made a significant contribution to increasing knowledge of the relationship between diet and the immune system, considering nutrient intake as a critical determinant of immunocompetence ${ }^{1}$. This association was confirmed after the recognition of long chain $n-3$ polyunsaturated fatty acids (PUFA) as nutrients that participate in the regulation of immune system functions ${ }^{2}$. Olive oil, a fundamental constituent of the Mediterranean diet, is also able to modulate the immune system, since it contains numerous components that possess some biological activities. Olive oil has been associated with the suppression of different immune functions, although less attention has been paid to the effects of monounsaturated fatty acids (MUFA), compared with PUFA, upon the immune system. Classically, MUFA have been considered as neutral fatty acids and have often been applied as placebo in studies investigating the anti-inflammatory properties of other fatty acids 3 . Overall, the action of MUFA on the human immune system has allowed their application in the resolution or attenuation of diseases characterized by inflammatory disorders ${ }^{4,5}$, in the reduction of cancer risk ${ }^{6}$ and in clinical nutrition ${ }^{7}$. This article will summarize the current state of knowledge concerning the effects and interactions of olive oil on immune system functions, as well as the action of this fat in the preservation of host immune defence.

\section{Immunomodulation by fatty acids}

Since the 1970s, a number of epidemiological studies have suggested that certain dietary fatty acids (particularly long-chain n-3 PUFA contained in oily fish and fish oils) affect the immune response in both animals and humans.
Early studies in Greenland Eskimos indicated the low prevalence of inflammatory disorders in this population ${ }^{8}$, and the reduction of death from ischemic heart disease, in spite of the consumption of diets high in fat and cholesterol ${ }^{9}$, or the low incidence of cancer $^{10}$. Despite their beneficial effects in the reduction of inflammatory disease prevalence, other studies have demonstrated that the administration of diets containing long-chain $n-3$ PUFA may contribute, at least in part, to the reduction of host resistance against infectious agents. Indeed, epidemiological investigations described a high incidence of tuberculosis in native Eski$\operatorname{mos}^{11}$, who consume a great amount of $n-3$ PUFA. These data are illustrative of the potential action of certain fatty acids, and of the consequences derived from an excessive immunosuppression. Nevertheless, this aspect requires more detailed investigation, because several studies have also shown that the administration of diets containing fish oil improves immune defence against infectious microorganisms ${ }^{12}$. It is possible that differences in experimental design may explain the disparities between studies.

Olive oil: a fat involved in the modulation of immune system functions

Olive oil is mainly composed of oleic acid, plus additional different chemical components such as sterols, alcohols, antioxidants, and other fatty acids (apart from oleic acid) of minor relevance. An interesting study examined the biological constituents of olive oil responsible for the modulation of the immune functions and revealed that the immunosuppressive effects attributed to olive oil are likely due to oleic acid rather than to other minor components of this fat $^{13}$. However, 
a recent study has demonstrated that the polyphenolic substances contained in olive oil possess anti-inflammatory properties $^{14}$.

Different studies investigating the effects of fatty acids on the immune system have demonstrated that a diet containing olive oil administered to animals is able to promote a significant reduction of lymphocyte proliferation in response to the mitogen concanavalin A (Con A) ${ }^{15}$. In contrast, human studies have produced conflicting results, where for example, the administration of a diet containing an increased amount of olive oil did not affect proliferation of mitogen-stimulated lymphocytes ${ }^{16}$. It is possible that the observed differences between animal and human studies may be attributed in part to the amount of MUFA administered. Thus, MUFA contributed approximately 25 to $30 \%$ of total energy in the animal studies, whereas diets constituted by MUFA supplied approximately $18 \%$ of total energy in human studies ${ }^{17}$. Although some animal investigations have reported a reduction of lymphocyte proliferation in response to Con $\mathrm{A}$, we did not find a significant effect of olive oil on the proliferation of murine lymphocytes stimulated with either Con A or lipopolysaccharide (LPS $)^{18}$. The specific factors that contribute to the contradictory results observed in both mice and humans should be elucidated in further research, which will help to explain the discrepancies in the findings published to date. However, it is important to note that other factors different from the amount of olive oil in the diet, such as ingestion of other types of nutrients, could undoubtedly be involved in the different experimental results observed between humans and animals.

Cytokine production is reduced after the administration of certain dietary lipids. These proteins regulate the growth and differentiation of different lymphocyte subsets and they activate and regulate cells that participate in the inflammatory response. Interleukin-2 (IL-2) is an important cytokine responsible for the proliferation of T-lymphocytes. Administration of diets containing olive oil for 8 or 12 weeks produced an increase in IL-2 production in mice ${ }^{19,20}$. IL-4 production, a cytokine with anti-inflammatory functions was increased in mice after the administration of a diet containing olive oil for 4 weeks $^{21}$. In contrast, the production of IL-10, a cytokine with similar functions to IL-4, was decreased after the administration of a diet containing olive oil, although the production of IL-10 was not different from that seen after feeding mice a low fat $\operatorname{diet}^{15}$. Finally, the concentration of IL-12, a cytokine that participates as a pro-inflammatory protein, was reduced in mice fed with diets containing olive oil ${ }^{21}$. Other cytokines are produced mainly by monocytes/macrophages. The synthesis of these proteins is also modulated by the administration of a diet containing olive oil. Thus, IL-1 production was diminished, whereas TNF- $\alpha$ or IL- 6 production were increased or not modified in mice 22,23 . Overall, diets containing olive oil are also related to the suppression of cytokine production, but this effect is not as severe as that produced by the administration of a fish oil-rich diet.

Natural killer (NK) cell activity is modulated by the action of certain dietary lipids. NK cells constitute a central lymphocyte subset found in blood and spleen that destroy virusinvaded cells or transformed cells. In animal studies, the administration of an olive oil diet reduced NK cell activity ${ }^{24}$. Comparison of data among animals fed different amounts of oleic acid showed a linear negative relationship, indicating that oleic acid is responsible for a reduction of $\mathrm{NK}$ cell activity in rats ${ }^{25}$. In fact, this activity is significantly reduced in mice fed with an olive oil diet after receiving LSTRA tumor transplantation (an ascitic Moloney virus-induced lymphoma), although the greatest suppression was observed in mice fed with a fish oil $\operatorname{diet}^{26}$. Once again, human studies have not confirmed the animal results; the measurement of $\mathrm{NK}$ cell activity after the administration for one or two months of a diet containing olive oil did not show significant differences from the control group, although the activity of these cells declined after two months of consuming of this $\operatorname{diet}^{16}$.

\section{Consequences derived from the administration of a diet containing olive oil in the modulation of the immune system}

\section{Resistance to infectious agents}

Several lines of evidence have demonstrated that the suppression of immune system functions exerted by certain dietary lipids may cause a reduction of host resistance to infection ${ }^{27-30}$. Obviously, available data only refer to experimental animals, and the effect of dietary lipids that may specifically modulate host defence to infectious pathogens in healthy humans has not been clearly established (see Tables 1 and 2). As previously described, early epidemiological studies reveal that the consumption of diets containing very high amounts of long chain $n-3$ PUFA increases the risk of infection and the incidence of tuberculosis in native Eskimos ${ }^{11}$, despite the beneficial effects in the reduction of inflammatory disorders ${ }^{4,8}$. Subsequently, experimental studies have demonstrated a significant reduction

Table 1. Summary of human studies examining the effects of olive oil on immune system function

$$
\begin{aligned}
& \text { At } \\
& \text { Adm } \\
& \text { Ad } \\
& \text { An } \\
& \text { Ab } \\
&
\end{aligned}
$$

Study characteristics

Administration of a diet containing olive oil $(18.4 \%$ of energy) to healthy middle-aged men for 2 months

Risk factors for rheumatoid arthritis in elderly subjects

Administration of olive oil ( $6.8 \mathrm{~g}$ oleic $\mathrm{acid} / \mathrm{d})$ to patients suffering from rheumatoid arthritis

Administration of extra virgin olive oil to healthy subjects

In vitro exposure of PBMC to an olive oil-based lipid emulsion

In vitro exposure of PBMC to an olive oil-based lipid emulsion

References

\section{Unmodified PBMC proliferative response. Suppressed NK}

cell activity. Reduced ICAM-1 expression.

Risk decreased by high consumption of olive oil

Altered in immune function associated with beneficial

effects on the progression of rheumatoid arthritis

Decreased markers of oxidative stress

Decreased production of pro-inflammatory cytokines

Maintenance of immunity and reduced inflammatory response
16

5

4

39

34

38

Abbreviation: PBMC, peripheral blood mononuclear cells; ICAM-1, intercellular adhesion molecule-1. 
Table 2. Summary of animal studies examining the effects of olive oil on immune system function

\begin{tabular}{|c|c|c|}
\hline Study characteristics & Findings of the study & References \\
\hline Rats fed a diet containing $200 \mathrm{~g} / \mathrm{kg}$ of olive oil for 10 weeks & Decreased spleen NK cell activity & 24 \\
\hline Mice fed a diet containing $150 \mathrm{~g} / \mathrm{kg}$ of olive oil for 12 weeks & Increased IL-2 and TNF- $\alpha$ production compared with a low fat diet & 23 \\
\hline $\begin{array}{l}\text { Rats fed diets containing } 200 \mathrm{~g} / \mathrm{kg} \text { olive oil, sunflower oil or } \\
\text { high oleic sunflower oil for } 6 \text { weeks }\end{array}$ & $\begin{array}{l}\text { The immunosuppressive effects attributed to an olive oil diet are mainly } \\
\text { due to oleic acid }\end{array}$ & 13 \\
\hline $\begin{array}{l}\text { Balb/c mice fed diets containing } 200 \mathrm{~g} / \mathrm{kg} \text { olive oil, fish oil or } \\
\text { hydrogenated coconut oil for } 4 \text { weeks and } \\
\text { subsequently infected with } L \text {. monocytogenes }\end{array}$ & $\begin{array}{l}\text { Production of IL-12 is not modified, but increased IL-4 production } \\
\text { after } L \text {. monocytogenes infection }\end{array}$ & 21 \\
\hline $\begin{array}{l}\text { C57B1/6 J mice fed a diet containing } 7 \%(\mathrm{w} / \mathrm{w}) \text { olive oil } \\
\text { diet for } 6 \text { weeks and injected with LPS }\end{array}$ & Decreased inflammatory response and improved survival & 40 \\
\hline $\begin{array}{l}\text { Rats received an olive oil-based lipid emulsion in a model } \\
\text { of Escherichia coli bacteraemia }\end{array}$ & $\begin{array}{l}\text { Preserved mononuclear phagocyte system, although mortality } \\
\text { is unaffected }\end{array}$ & 35 \\
\hline
\end{tabular}

Abbreviations: NK, natural killer; LPS, lipopolysaccharide; IL, interleukin; TNF, tumor necrosis factor.

of survival percentage as well as an increase of viable bacteria in the spleen ${ }^{31}$ or $\operatorname{liver}^{32}$ after the administration of diets containing long chain $n-3$ PUFA to mice experimentally infected with a virulent pathogen. These data indicate that the suppression of the immune system caused by these fatty acids leads to a reduction of host resistance against infectious microorganisms ${ }^{27-30}$. Although the mechanism by which some dietary lipids affect host resistance to infection are not clearly defined, changes in pro-inflammatory eicosanoid and cytokine production may be particularly involved in these processes.

Numerous investigations have reported the involvement of long-chain $n$-3 PUFA in the modulation of natural resistance against Salmonella typhimurium serovar Typhimurium, Mycobacterium tuberculosis, Listeria monocytogenes, influenza virus or parasites ${ }^{29,30}$. Currently, the information on the effects of olive oil on host resistance is very poor, but the results obtained have indicated that the administration of diets containing MUFA are able to reduce infection severity and to prolong survival in murine models after the challenge with L. monocytogenes. In addition, the recovery of viable bacteria from spleen ${ }^{31}$ of mice is reduced at an early stage of infection. Finally, bactericidal activity of peritoneal cells from mice fed a diet containing olive oil is more efficient than that from mice fed a diet containing fish oil ${ }^{33}$. In contrast, the number of adhering bacteria as well as the number of invading bacteria is substantially larger in the group fed a diet containing olive oil ${ }^{18}$.

An important cytokine involved in the activation of Th1 response is IL-12, which plays a relevant role in the elimination of intracellular bacteria. Thus, IL-12 production is not initially reduced in mice fed a diet containing olive oil, although the production of other pro-inflammatory cytokines such as IL-1, IL-6 and TNF- $\alpha$ was modified after L. monocytogenes infection, especially at $24 \mathrm{~h}$ of challenge (Fig. 1).

The administration of a diet containing olive oil in mice infected with L. monocytogenes and intraperitoneally treated with cyclophosphamide, an immunosuppressive agent, does not have an effect as great as a fish oil diet on the survival of mice after infection, or on the recovery of viable bacteria from mice spleen and liver. It is possible that the immunosuppression exerted by diets containing fish oil is aggravated in this model, whereas in our experience an olive oil diet moderately reduces host resistance to infection (unpublished results).

\section{Olive oil in clinical nutrition}

Lipid emulsions constitute an essential component of total parenteral nutrition, which represents an indispensable strategy to improve nutritional status of critically ill patients. The interaction between fatty acids and the immune system has increased the interest in the manipulation of fatty acid composition in lipid emulsions, which have widely been used in clinical practice for over 30 years. The administration of an olive oil-containing emulsion (ClinOleic or SMOFLipid) appears to be more beneficial to immune system functions than soybean oil-based emulsions, because it does not alter inflammatory cytokine production. This property constitutes an important factor that allows the administration of this lipid emulsion in patients for whom a reduction of immune resistance constitutes a drastic event, because they are at a high risk of infection ${ }^{34}$. In fact, with the purpose of finding a lipid emulsion capable of protecting mononuclear phagocyte system functions, a study revealed that the administration of a lipid emulsion enriched with olive oil to rats infected with Escherichia coli is efficient and may be used in the preservation of mononuclear phagocyte system functions ${ }^{35}$.

The lipid emulsions most commonly applied as nutritional therapy support contain $n-6$ PUFA such as safflower oil or soybean oil, but they may be involved in adverse effects on the immune system, especially when are administered in high doses over a short time period. In fact, an excess of $n-6$ PUFA and the low amount of $n-3$ PUFA are related to adverse effects on immunological functions ${ }^{7}$. ClinOleic offers clinical advantages in severally burned patients, with improved liver functions after administration ${ }^{36}$. Therefore, emulsions containing olive oil are an important alternative to soybean oil in parenteral nutrition, because an olive oilbased lipid emulsion offers better maintenance of immunity and reduces the inflammatory response $\mathrm{s}^{37,38}$. 

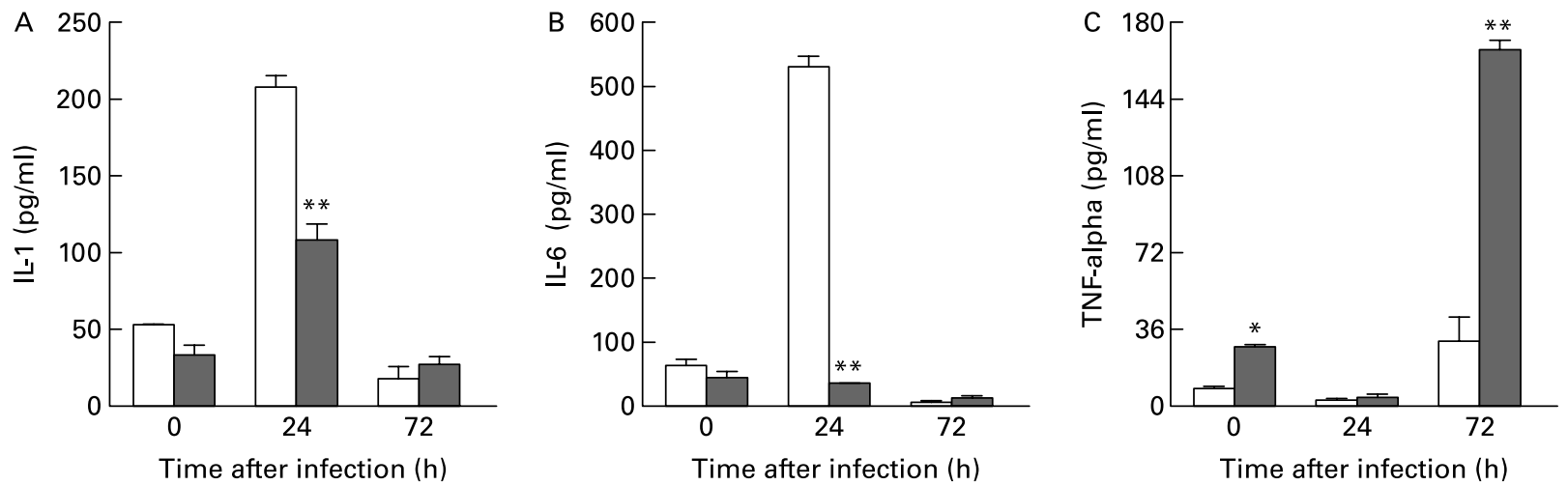

Fig. 1. Pro-inflammatory cytokine concentrations in sera from mice fed an olive oil diet or a low fat diet (control diet) and experimentally infected with Listeria monocytogenes. The concentration of interleukin-1 (IL-1), interleukin-6 (IL-6) and tumour necrosis factor- $\alpha$ (TNF- $\alpha$ ) was measured in the serum of Balb/c mice fed with a low fat diet (open bars) or with an olive oil diet (close bars) for four weeks. After the feeding period, animals were experimentally infected with $L$. monocytogenes and the serum was collected at 0,24 and $72 \mathrm{~h}$ of challenge. Significant differences (two-way ANOVA) between experimental groups in each time are indicated as follow: ${ }^{\star} P<0.05 ;{ }^{\star *} P<0.001$.

\section{Concluding remarks}

Diets containing olive oil may exert beneficial effects when they have been applied in the resolution of inflammatory disorders. Experimental studies have indicated that the immunomodulatory action of olive oil is due to oleic acid, but recent investigations have suggested that anti-inflammatory properties are also attributed to phenolic compounds. The immunosuppressive effects related to olive oil diet administration in animals are not as great as those produced by long chain $n-3$ PUFA, which are considered as the most immunosuppressive fatty acids. The biological properties exhibited by MUFA may result in a moderate reduction of host defence to pathogens. Therefore, it is important to determine the effects produced by olive oil in patients at risk of sepsis, to ensure that olive oil does not impair host immune resistance against infectious microorganisms.

\section{Conflict of interest statement}

MAP owned a research contract ("Juan de la Cierva" from the Ministry of Education and Science). EP was the recipient of a predoctoral fellowship from the Ministry of Education and Science (Spain). We are grateful to Excelentisima Diputación Provincial de Jaén by supporting a part of this publication. The authors have no conflicts of interest to report. All authors contributed to co-write the manuscript. MAP and MAdP read and approved the final version of this manuscript.

\section{References}

1. Klasing KC \& Leshchinsky TV (2000) Interactions between nutrition and immunity. In Nutrition and Immunity, [ME Gershwin, JB German and CL Keen, editors]. Totowa: Humana Press Inc.

2. Calder PC (2003) N-3 polyunsaturated fatty acids and inflammation: from molecular biology to the clinic. Lipids 38, $343-352$.

3. Virella G, Fourspring K, Hyman B, Haskill-Stroud R, Long L, Virella I, La Via M, Gross AJ \& Lopes-Virella M (1991) Immunosuppressive effects of fish oil in normal volunteers: correlation with the in vitro effects of eicosapentaenoic acid on human lymphocytes. Clin Immunol Immunopathol 61, 161-176.
4. Kremer J, Lawrence DL, Jubiz W, DiGiacomo R, Rynes R, Bartholomew LE \& Sherman M (1990) Dietary fish oil and olive oil supplementation in patients with rheumatoid arthritis: clinical and immunologic effects. Arthritis Rheum 33, 810-820.

5. Linos A, Kaklamanis E, Kontomerkos A, Koumantaki Y, Gazi S, Vaiopoulos G, Tsokos GC \& Kaklamanis P (1991) The effect of olive oil and fish consumption on rheumatoid arthritis: a case control study. Scand J Rheumatol 20, 419-426.

6. Martin-Moreno JM, Willett WC, Gorgojo L, Banegas JR, Rodriguez-Artalejo F, Fernandez-Rodriguez JC, Maisonneuve P \& Boyle P (1994) Dietary fat, olive oil intake and breast cancer risk. Int J Cancer 58, 774-780.

7. Sala-Vila A, Barbosa VM \& Calder PC (2007) Olive oil in parenteral nutrition. Curr Opin Clin Nutr Metab Care 10, $165-174$.

8. Kromann N \& Green A (1980) Epidemiological studies in the Upernavik district, Greenland. Incidence of some chronic diseases 1950-1974. Acta Med Scand 208, 401-406.

9. Kromhout D (1989) N-3 fatty acids and coronary heart disease: epidemiology from Eskimos to Western populations. J Intern Med Suppl 225, 47-51.

10. Blot WJ, Lanier A, Fraumeni JF Jr \& Bender TR (1975) Cancer mortality among Alaskan natives, 1960-69. J Natl Cancer Inst 55, 547-554.

11. Kaplan GJ, Fraser RI \& Comstock GW (1971) Tuberculosis in Alaska 1970. Am Rev Respir Dis 105, 920-926.

12. Blok WL, Vogels MT, Curfs JH, Eling WM, Buurman WA \& van der Meer JW (1992) Dietary fish-oil supplementation in experimental gram-negative infection and in cerebral malaria in mice. J Infect Dis $\mathbf{1 6 5}, 898-903$.

13. Jeffery NM, Yaqoob P, Newsholme EA \& Calder PC (1997) The effects of olive oil upon rat serum lipid levels and lymphocyte functions are due to oleic acid. Ann Nutr Metab 40, 71-80.

14. Beauchamp GK, Keast RS, Morel D, Lin J, Pika J, Han Q, Lee CH, Smith AB \& Breslin PA (2005) Phytochemistry: ibuprofen-like activity in extra-virgin olive oil. Nature 437, 45-46.

15. Yaqoob P, Newsholme EA \& Calder PC (1994) The effect of dietary lipid manipulation on rat lymphocyte subsets and proliferation. Immunology 82, 603-610.

16. Yaqoob P, Knapper JA, Webb DA, Williams CM, Newsholme EA \& Calder PC (1998) Effect of olive oil on immune function in middle-aged men. Am J Clin Nutr 67, 129-135.

17. Yaqoob P (2002) Monounsaturated fatty acids and immune function. Eur J Clin Nutr 56, S9-S13. 
18. Puertollano MA, de Pablo MA \& Alvarez de Cienfuegos G (2002) Relevance of dietary lipids as modulators of immune functions in cells infected with Listeria monocytogenes. Clin Diagn Lab Immunol 9, 352-357.

19. Yaqoob P \& Calder PC (1995) The effects of dietary lipid manipulation on the production of murine $\mathrm{T}$ cell-derived cytokines. Cytokine 7, 548-553.

20. de Pablo MA, Ortega E, Gallego AM, Alvarez C, Pancorbo PL \& Alvarez de Cienfuegos G (1998) Influence of diets containing olive oil, sunflower oil or hydrogenated coconut oil on the immune response of mice. J Clin Biochem Nutr 25, 11-23.

21. Puertollano MA, Puertollano E, Ruiz-Bravo A, Jimenez-Valera M, de Pablo MA \& Alvarez de Cienfuegos G (2004) Changes in the immune functions and susceptibility to Listeria monocytogenes infection in mice fed dietary lipids. Immunol Cell Biol 82, 370-376.

22. Yaqoob P \& Calder PC (1995) Effects of dietary lipid manipulation upon inflammatory mediator production by murine macrophages. Cell Immunol 163, 120-128.

23. de Pablo MA, Ortega E, Gallego AM, Alvarez C, Pancorbo PL \& Alvarez de Cienfuegos G (1998) The effect of dietary fatty acid manipulation on phagocytic activity and cytokine production by peritoneal cells from Balb/c mice. J Nutr Sci Vitaminol 44, 57-67.

24. Yaqoob P, Newsholme EA \& Calder PC (1994) Inhibition of natural killer cell activity by dietary lipids. Immunol Lett 41, 241-247.

25. Jeffery NM, Cortina M, Newsholme EA \& Calder PC (1997) Effects of variations in the proportions of saturated, monounsaturated and polyunsaturated fatty acids in the rat diet on spleen lymphocyte functions. Br J Nutr 77, 805-823.

26. Puertollano MA, Algarra I, Ortega E, de Pablo MA \& Alvarez de Cienfuegos G (2001) Loss of cell natural killer cell activity after murine tumor transplantation appears as a consequence of dietary lipid administration. Anticancer Res 21, 2697-2702.

27. de Pablo MA, Puertollano MA \& Alvarez de Cienfuegos G (2000) Immune cell functions, lipids and host natural resistance. FEMS Immunol Med Microbiol 29, 323-328.

28. de Pablo MA \& Alvarez de Cienfuegos G (2000) Modulatory effects of dietary lipids on immune system functions. Immunol Cell Biol 78, 31-39.

29. de Pablo MA, Puertollano MA \& Alvarez de Cienfuegos G (2002) Biological and clinical significance of lipids as modulators of immune system functions. Clin Diagn Lab Immunol 9, 945-950.
30. Fritsche K (2006) Fatty acids as modulators of the immune response. Annu Rev Nutr 26, 45-73.

31. de Pablo MA, Puertollano MA, Gálvez A, Ortega E, Gaforio JJ \& Alvarez de Cienfuegos G (2000) Determination of natural resistance of mice fed dietary lipids to experimental infection induced by Listeria monocytogenes. FEMS Immunol Med Microbiol 27, 127-133.

32. Fritsche KL, Shahbazian LM, Feng C \& Berg JN (1997) Dietary fish oil reduces survival and impairs bacterial clearance in $\mathrm{C} 3 \mathrm{H} /$ Hen mice challenged with Listeria monocytogenes. Clin Sci (Lond) 92, 95-101.

33. Puertollano MA, de Pablo MA \& Alvarez de Cienfuegos G (2001) Immunomodulatory effects of dietary lipids alter host natural resistance of mice to Listeria monocytogenes infection. FEMS Immunol Med Microbiol 32, 47-52.

34. Reimund JM, Scheer O, Muller CD, Pinna G, Duclos B \& Baumann R (2004) In vitro modulation of inflammatory cytokine production by three lipid emulsions with different fatty acid compositions. Clin Nutr 23, 1324-1332.

35. Garnacho-Montero J, Ortiz-Leyba C, Garnacho-Montero MC, García-Garmendia JL, Pérez-Paredes C, Moyano-Del Estad MR, Barrero-Almodóvar A \& Jiménez-Jiménez FJ (2002) Effects of three intravenous lipid emulsions on the survival and mononuclear phagocyte function of septic rats. Nutrition 18, 751-754.

36. Garcia de Lorenzo A (2005) Monounsaturated fatty acid-based lipid emulsions critically ill patients are associated with fewer complications. Br J Nutr 95, 1029.

37. Moussa M, Le Boucher J, García J, Thaczok J, Ragab J, Dutot G, Ohayon E, Ghisolfi J \& Thouvenot JP (2000) In vivo effects of olive oil-based lipid emulsion on lymphocyte activation in rats. Clin Nutr 19, 49-54.

38. Granato D, Blum S, Rössle C, Le Boucher J, Malnoe A \& Dutot G (2000) Effects of parenteral lipid emulsions with different fatty acid composition on immune cell functions in vitro. $J$ Parent Ent Nutr 24, 113-118.

39. Bogani P, Galli C, Villa M \& Visioli F (2007) Postprandial antiinflammatory and antioxidant effects of extra virgin olive oil. Atherosclerosis 190, 181-186.

40. Leite MS, Pacheco P, Gomes RN, Guedes AT, Castro-FariaNeto HC, Bozza PT \& Koatz VL (2005) Mechanisms of increased survival after lipopolysaccharide-induced endotoxic shock in mice consuming olive oil-enriched diet. Shock 23, $173-178$. 